\title{
Identification of two glycosylated components of Mycoplasma penetrans: a surface-exposed capsular polysaccharide and a glycolipid fraction
}

\author{
Olivier Neyrolles, ${ }^{1}$ Catherine Brenner, ${ }^{1}$ Marie-Christine Prevost, ${ }^{1}$ \\ Thierry Fontaine, ${ }^{2}$ Luc Montagnier $^{1}$ and Alain Blanchard ${ }^{1}$
}

Author for correspondence: Alain Blanchard. Tel: +331406131 31. Fax: +33140613465. e-mail: ablancha@pasteur.fr

Unité d'Oncologie Virale ${ }^{1}$ and Laboratoire des Aspergillus 2 , Institut Pasteur, 28, rue du Dr Roux, 75724 Paris Cedex 15, France

\begin{abstract}
Among the wall-less mycoplasmas only a few species have been identified with a capsule at their cell surface. Mycoplasma penetrans is a recently identified mycoplasma with unique morphology, isolated from HIV-infected patients. Using transmission electron microscopy, it was found that $M$. penetrans is surrounded by capsular material $11 \mathrm{~nm}$ (strain GTU-54-6A1) to $30 \mathrm{~nm}$ (strain HF-2) thick, which can be stained with ruthenium red and labelled with cationized ferritin. The polysaccharide composition of this capsule was indicated by its staining with periodic acid-thiocarbohydrazide silver proteinate and the abolition of ruthenium red staining of the cell surface by neuraminidase treatment. In addition, proteinase $K$ treatment of the $M$. penetrans cells resulted in removal of the capsule, suggesting that polypeptides may contribute in anchoring it to the membrane or in its stability. Two different types of glycosylated material were detected in mycoplasma extracts by SDS-PAGE and periodic acid-Schiff staining. The first component was a high-molecular-mass material, which was heat- and proteinase-K-labile and which probably constitutes the capsular polymer. The other component was a low-molecular-mass glycolipid fraction, which was proteinase-K-, heat- and EDTA-resistant. The identification of a capsule at the $M$. penetrans cell surface is of particular interest for a mycoplasma which has been shown to adhere to various host cells and to penetrate into their intracellular compartments. The capsule may have significance in the pathogenesis of disease associated with infection by this organism.
\end{abstract}

Keywords: Mollicutes, Mycoplasma penetrans, capsule, polysaccharide, glycolipid

\section{INTRODUCTION}

A very wide range of bacteria, including Escherichia coli, Klebsiella spp., Pseudomonas spp., Haemophilus spp., Salmonella spp., Bacillus spp., clostridia, pneumococci, streptococci and staphylococci, produce polysaccharide capsules (Kasper, 1986; Whitfield, 1988). The capsule usually consists of high-molecular-mass exopolysaccharides containing acidic residues. These polymers are exposed at, and attached to, the extra-

\footnotetext{
Abbreviations: GLF, glycolipid fraction; HMM, high-molecular-mass material; PAS, periodic acid-Schiff reagent; PATAg, periodic acidthiocarbohydrazide silver proteinate; PBMC, peripheral blood mononuclear cells; RR, ruthenium red.
}

cellular surface of the bacteria. Due to their anionic properties, they appear as electron-dense material in transmission electron micrographs following ruthenium red (RR) treatment. Capsules have been implicated in bacterial virulence, cell adhesion and invasion (Moxon \& Kroll, 1990), and also in resistance to complementmediated lysis and phagocytosis (Cross, 1990). Bacterial capsules are often poor immunogens if not combined with Freund's adjuvant and are thought to induce a Tcell-independent immune response (Kasper, 1986).

A few species of the Class Mollicutes (trivial name, mycoplasmas), including Mycoplasma gallisepticum (Tajima et al., 1982), M. meleagridis (Green \& Hanson, 1973), M. mycoides subsp. mycoides (Buttery \& Plackett, 1960), M. dispar (Howard \& Gourlay, 1974), 
M. hominis (Furness et al., 1976), M. hyopneumoniae (Tajima \& Yagihashi, 1982), M. pneumoniae (Wilson \& Collier, 1976), M. pulmonis (Taylor-Robinson et al., 1981) and Ureaplasma urealyticum (Robertson \& Smook, 1976), possess extramembraneous RR-stainable capsule material. A lipoglycan, not necessarily revealed by RR staining, has also been described in several mycoplasma species (Smith, 1992). The biochemical composition of the capsular polymers of only a few mycoplasma species has been determined. The capsules from M. mycoides subsp. mycoides, $M$. mycoides subsp. capri and $M$. dispar were identified as a polymer of 1,6$\beta$-linked galactose residues (Buttery, 1970), a polyglucan (Jones et al., 1965) and a polymer of galacturonic acid (Rosenbusch \& Minion, 1992), respectively. By analogy with similar surface material from other bacterial species, mycoplasma capsules were suggested to be associated with virulence and the ability of these species to evade the host immune response and phagocytosis (Marshall et al., 1995; Rosenbusch \& Minion, 1992). Indeed, the ability of $M$. byopneumoniae to produce pulmonary lesions in pigs was lost when capsule thickness was reduced following passaging in vitro (Tajima \& Yagihashi, 1982). In addition, it was shown for M. dispar (Almeida et al., 1992) that there is a correlation between the presence of capsule and the resistance of mycoplasma cells to phagocytosis.

Mycoplasma penetrans was only recently isolated, initially from HIV-infected patients, and has unique morphology (Lo et al., 1991). It is cytopathic and capable of adhesion to, and invasion of, mammalian epithelial cells (Andreev et al., 1995; Giron et al., 1996; Lo et al., 1993). It is associated with HIV infection, at least among homosexual patients (Grau et al., 1995; Wang et al., 1993). In addition, Sasaki et al. (1995) showed that $M$. penetrans is capable of inducing the in vitro proliferation of $\mathrm{CD}^{+}$and $\mathrm{CD}^{+} \mathrm{T}$ lymphocytes from HIV-seronegative and -seropositive subjects. Finally, different mycoplasma species, including $M$. penetrans, have been proposed to act as co-factors during HIV infection, accelerating the evolution of this retroviral disease (Blanchard et al., 1997; Blanchard \& Montagnier, 1994; Brenner et al., 1996).

The aim of this study was to examine the nonproteinaceous cell surface components of $M$. penetrans in order to gain a greater understanding of the components involved in its interaction with host cells.

\section{METHODS}

Mycoplasma strains and culture. $M$. penetrans strain GTU54-6A1 (type strain), originally isolated by S.-C. Lo (Armed Forces Institute of Pathology, Bethesda, MD, USA), was obtained from J. G. Tully (National Institute of Allergy and Infectious Diseases, Frederick, MD, USA) and was cultivated in SP-4 medium (Tully et al., 1977) supplemented with $10 \%$ (v/v) foetal calf serum (Gibco-BRL). For some experiments, $\left[1-{ }^{14} \mathrm{C}\right]$ palmitic acid (Amersham) or $\left[{ }^{32} \mathrm{P}_{3} \mathrm{H}_{3} \mathrm{PO}_{4}\right.$ (Amersham) was added to the medium $\left[9.25 \times 10^{4} \mathrm{~Bq}\right.$ (ml culture medium) $\left.{ }^{-1}\right]$. Another strain of $M$. penetrans (strain HF-2; provided by A. Yañez, University of Puebla, Puebla, Mexico) was also used in some experiments and was cultivated as indicated above for the type strain. Strain HF-2 was isolated from a tracheal aspirate sample collected from a patient with a primary antiphospholipid syndrome (A. Yañez and others, unpublished).

Experimental $M$. penetrans infection of cultured human peripheral blood mononuclear cells (PBMC). PBMC were isolated from the fresh blood of a healthy donor by centrifugation over Ficoll-Paque Plus (Pharmacia). PBMC were cultured for $24 \mathrm{~h}$ in RPMI 1640 supplemented with $10 \%$ heatinactivated foetal calf serum, $2 \mathrm{mM} \mathrm{L}$-glutamine and $10 \mu \mathrm{g}$ phytohaemagglutinin A (PHA) $\mathrm{ml}^{-1}$ at $37^{\circ} \mathrm{C}$ in a humidified atmosphere containing $5 \% \mathrm{CO}_{2}$. The $\mathrm{PBMC}$ were then transferred to the same medium without PHA and $M$. penetrans was added at a multiplicity of infection of about 10 colour changing units per cell. After $24 \mathrm{~h}$ of co-culture, the cells were processed for electron microscopy as described below.

Glycolipid fraction (GLF) isolation. GLF was prepared as follows: mycoplasma cells were recovered by centrifugation $\left(12000 \mathrm{~g}, 20 \mathrm{~min}, 4^{\circ} \mathrm{C}\right)$ and washed twice in PBS $(0.145 \mathrm{M}$ sodium choride, $0 \cdot 15 \mathrm{M}$ sodium phosphate). Proteinase $\mathrm{K}$ was added to the mycoplasma cell suspension [1 $\mu \mathrm{g}$ proteinase $\mathrm{K}$ $\left.(2.5 \mu \mathrm{g} \text { protein })^{-1}\right]$ and the mixture was incubated for $2 \mathrm{~h}$ at $56^{\circ} \mathrm{C}$. Proteinase $\mathrm{K}$ was then inactivated by heating for $15 \mathrm{~min}$ at $95^{\circ} \mathrm{C}$. The sample was then dialysed $(1: 1000)$ against PBS (or water for preparations being analysed by gas chromatography) for $48 \mathrm{~h}$ at $4^{\circ} \mathrm{C}$ in $12-14 \mathrm{kDa}$ cut-off dialysis tubing (Spectrum Medical Industries), with several changes of the dialysis buffer. The absence of protein was verified for each preparation of GLF by SDS-PAGE and Coomassie-blue staining.

Transmission electron microscopy. Mycoplasmas, or mycoplasma-infected PBMC, were harvested by centrifugation $\left(8000 \mathrm{~g}, 15 \mathrm{~min}, 4^{\circ} \mathrm{C}\right)$, washed twice in 0.1 vol. PBS and fixed for $1 \mathrm{~h}$ at room temperature in $0.1 \mathrm{M}$ cacodylate buffer containing $0.075 \% \mathrm{RR}$ and $3 \%(\mathrm{v} / \mathrm{v})$ glutaraldehyde. The pellets were then washed three times in $0.1 \mathrm{M}$ cacodylate buffer containing $0.075 \% \mathrm{RR}$ and post-fixed for $2 \mathrm{~h}$ at room temperature in $0.1 \mathrm{M}$ cacodylate buffer containing $0.075 \% \mathrm{RR}$ and $1 \%(\mathrm{v} / \mathrm{v})$ osmium tetroxide (Sigma). The pellets were washed three times in water and dehydrated through a graded ethanol series. The resulting pellets were embedded in Epon 812 resin. In some experiments the mycoplasma cells were treated for $30 \mathrm{~min}$ at $37^{\circ} \mathrm{C}$ with either proteinase $\mathrm{K}[2 \mu \mathrm{g}$ proteinase $\mathrm{K}$ ( $\mu \mathrm{g}$ protein $)^{-1}$ ] or Vibrio cholerae neuraminidase $\left[0 \cdot 1 \mathrm{U}(120 \mu \mathrm{g} \text { protein })^{-1}\right]$ prior to fixation.

For ferritin labelling, the mycoplasma pellets were fixed for $1 \mathrm{~h}$ in $0.1 \mathrm{M}$ cacodylate buffer containing $2.5 \%$ glutaraldehyde and then incubated in a $1 \mathrm{mg} \mathrm{ml}^{-1}$ cationized ferritin solution (Sigma) for $1 \mathrm{~h}$ at room temperature. The pellets were then washed three times in $0 \cdot 1 \mathrm{M}$ cacodylate buffer and post-fixed by incubation for $1 \mathrm{~h}$ at room temperature in a $0.1 \mathrm{M}$ cacodylate buffer containing $2 \%$ osmium tetroxide. Finally, samples were washed, dehydrated and embedded as described above.

For periodic acid-thiocarbohydrazide silver proteinate (PATÄ) staining, the procedure described by Thiery (1967) was followed. Briefly, ultrathin sections of mycoplasma cells mounted on gold grids were treated for 25 min with $1 \%$ periodic acid and then rinsed three times in distilled water. The grids were incubated in $20 \%(\mathrm{v} / \mathrm{v})$ acetic acid containing $0.2 \%$ thiocarbohydrazide for $36 \mathrm{~h}$ and then incubated in a series of decreasing concentrations of acetic acid followed by three washes in water. Finally, the grids were floated on $1 \%$ silver proteinate (Fluka Biochemica) for $30 \mathrm{~min}$ in the dark and then rinsed three times with water. In control sections, the 
periodic acid treatment was omitted and the samples were incubated in $10 \%(\mathrm{v} / \mathrm{v}) \mathrm{H}_{2} \mathrm{O}_{2}$ for $20 \mathrm{~min}$ and then processed as described above.

Thin sections were examined with a JEOL 1200EX 2 electron microscope.

Electrophoresis and staining procedures. SDS-PAGE was performed through a $4 \%$ acrylamide/bisacrylamide $(29: 1$, $\mathrm{w} / \mathrm{w})$ stacking gel, and a $17 \%$ acrylamide/bisacrylamide (29:1, w/w) separating gel according to the method of Laemmli (1970). For higher resolution of glycoconjugates, Tricine-SDS-PAGE was used as described by Lesse et al. (1990). The M. penetrans cells or extracts were solubilized in the SDS-PAGE sample cocktail and loaded on the gels after heating for $5 \mathrm{~min}$ at $95^{\circ} \mathrm{C}$. This heating treatment was omitted in some experiments as indicated. Triton X-114 extraction was performed as described by Ferris et al. (1995).

Glycoconjugates in gels were stained with the periodic acidSchiff reagent (PAS) as described by Gerard (1990). The gels were then washed successively in $7 \%$ acetic acid for $24 \mathrm{~h}$ and in $10 \%$ acetic acid $/ 40 \%$ methanol for $2 \mathrm{~h}$ and then stained with Coomassie blue R250. Apparent molecular masses were determined by comparison with the electrophoretic mobility of low-molecular-mass polypeptide markers (Pharmacia Biotech). Autoradiography was performed using Hyperfilm-MP (Amersham), and a phosphoimager radioanalytical imaging system (Molecular Dynamics) was used to quantify the radioactive signals.

Quantification of sugar in GLF and protein in cellular extracts. Sugars from $M$. penetrans GLF obtained after the dialysis step were determined using a modification of the procedure described by Kirkeby et al. (1992). Briefly, GLF was oxidized by adding 0.1 vol. $0.02 \%$ periodic acid $/ 7 \%$ acetic acid and incubating for $2 \mathrm{~h}$ at $37^{\circ} \mathrm{C} ; 0.1 \mathrm{vol}$. Schiff reagent was then added and the solution incubated for $30 \mathrm{~min}$ at room temperature. The $A_{550}$ was measured and compared to a standard glycogen solution. This procedure did not allow the detection of mono- or disaccharides (Kirkeby et al., 1992). The results were expressed as $\mu \mathrm{g}$ glycogen equivalents $\mathrm{ml}^{-1}$.

The protein concentration of cell extracts was measured using the Micro BCA Protein Assay Reagent kit (Pierce).

Determination of GLF sugar composition using GLC. The sugar composition of $M$. penetrans GLF was determined by GLC analysis. Monosaccharides were released from freezedried GLF by methanolysis and hydrolysis with mesoinositol as the internal standard. Methanolysis was performed by incubating in $0.5 \mathrm{M} \mathrm{HCl}$ in anhydrous methanol (total volume: $0.5 \mathrm{ml}$ ) for $24 \mathrm{~h}$ at $80^{\circ} \mathrm{C}$. The $\mathrm{pH}$ was adjusted to 6.0 by adding silver carbonate. The free amine groups of aminecontaining sugars were $N$-acetylated by adding $20 \mu$ acetic anhydride and incubating overnight at room temperature in the dark. The samples were centrifuged, the methanol phase evaporated under a nitrogen stream and the dried residue trimethylsilylated in $100 \mu \mathrm{l} 50 \%$ (v/v) pyridine/N,O-bis(trimethylsilyl)trifluoroacetamide for $2 \mathrm{~h}$ at room temperature according to Kamerling et al. (1975). Hydrolysis was performed by incubating with $0.5 \mathrm{ml} 4 \mathrm{M}$ trifluoroacetic acid for $4 \mathrm{~h}$ at $100^{\circ} \mathrm{C}$. After evaporation of the reagent under vacuum, the monosaccharides were reduced by treatment with $1 \mathrm{mg}$ $\mathrm{NaBH}_{4}$ in $500 \mu \mathrm{l} 0 \cdot 1 \mathrm{M} \mathrm{NH}_{4} \mathrm{OH}$ for $2 \mathrm{~h}$ at room temperature. The excess $\mathrm{NaBH}_{4}$ was eliminated by increasing the $\mathrm{pH}$ to 6.0 by addition of acetic acid and the borate salts were removed by co-distillation with methanol using a rotary evaporator. The dried residue was acetylated by $50 \mu \mathrm{l}$ pyridine, $200 \mu \mathrm{l}$ acetic acid overnight at room temperature. The reagents were removed under a nitrogen stream in the presence of toluene and the residual alditol acetates were dissolved in methanol according to Sadawardeker $e t$ al. (1965). GLC was performed on a Delsi 200 instrument with a flame ionization detector using a capillary column $(25 \mathrm{~m} \times 0.2 \mathrm{~mm})$ filled with DB-1; gas vector: helium, 0.8 bar $(80 \mathrm{kPa})$; column temperature: $120-240^{\circ} \mathrm{C}$ at $2^{\circ} \mathrm{C} \mathrm{min}^{-1}$.

\section{RESULTS}

\section{Identification of a capsule at the $M$. penetrans surface}

RR staining or binding of cationized ferritin revealed the presence of an 11-13 nm thick layer uniformly coating the outer surface of the $M$. penetrans plasma membrane (Fig. 1a, b). It should be noted that this material also covered membrane blebs, structures previously described by others (Giron et al., 1996), which seemed to be released from the mycoplasma cell surface (Fig. 1b). Although the thickness of this layer or capsule was similar in different preparations of the $M$. penetrans type strain, it was twice as thick $(25-30 \mathrm{~nm})$ in strain HF-2 (Fig. 2b). The RR staining and the labelling with cationized ferritin indicated that the capsule was composed of anionic polymers. In addition, the polysaccharide composition of this material was demonstrated by two independent experiments: (i) the capsule could not be stained with RR after treatment of the cells with neuraminidase (Fig. 2e) and (ii) the capsule was stained with the PATAg reagent, which is specific for polysaccharides (Fig. 2f). Although these results indicated that the capsule contained polysaccharides, they did not exclude the possibility that other components played a role in anchoring it to the membrane or in its stability. Indeed, proteinase $\mathrm{K}$ treatment of the mycoplasma cells resulted in the disappearance of the capsule (Fig. 2d), whereas it was not affected when the cells were incubated under the same conditions $\left(37^{\circ} \mathrm{C}, 30 \mathrm{~min}\right)$ without protease (Fig. $2 \mathrm{c}$ ). The M. penetrans capsule could also be detected by RR staining when the mycoplasmas were incubated with eukaryotic cells and was found to occupy the space between the two plasma membranes (Fig. 2a).

\section{Detection of $\boldsymbol{M}$. penetrans glycoconjugates}

To identify the compound(s) stained during transmission electron microscopy by the PATAg reagent, various extracts of $M$. penetrans were analysed by Tricine-SDS-PAGE and polysaccharides identified with PAS (Fig. 3). A high-molecular-mass PAS-stainable material (HMM) from a whole-cell extract was found in the stacking gel (Fig. 3, lane 5). This material was heatlabile as demonstrated by its disappearance when the whole-cell SDS extract was heated before loading $(5 \mathrm{~min}$ at $95^{\circ} \mathrm{C}$; Fig. 3, lane 1). In addition, the HMM could not be detected in the gel after proteinase $\mathrm{K}$ treatment of the cells (Fig. 3, lane 3). Concomitant with this disappearance, some PAS-stainable material, which did not migrate into the gel, was detected at the bottom of the well. In a control experiment, using the same conditions of incubation $\left(30 \mathrm{~min}, 37^{\circ} \mathrm{C}\right)$, the HMM did not disappear when the protease was omitted (Fig. 3, lane 2). 

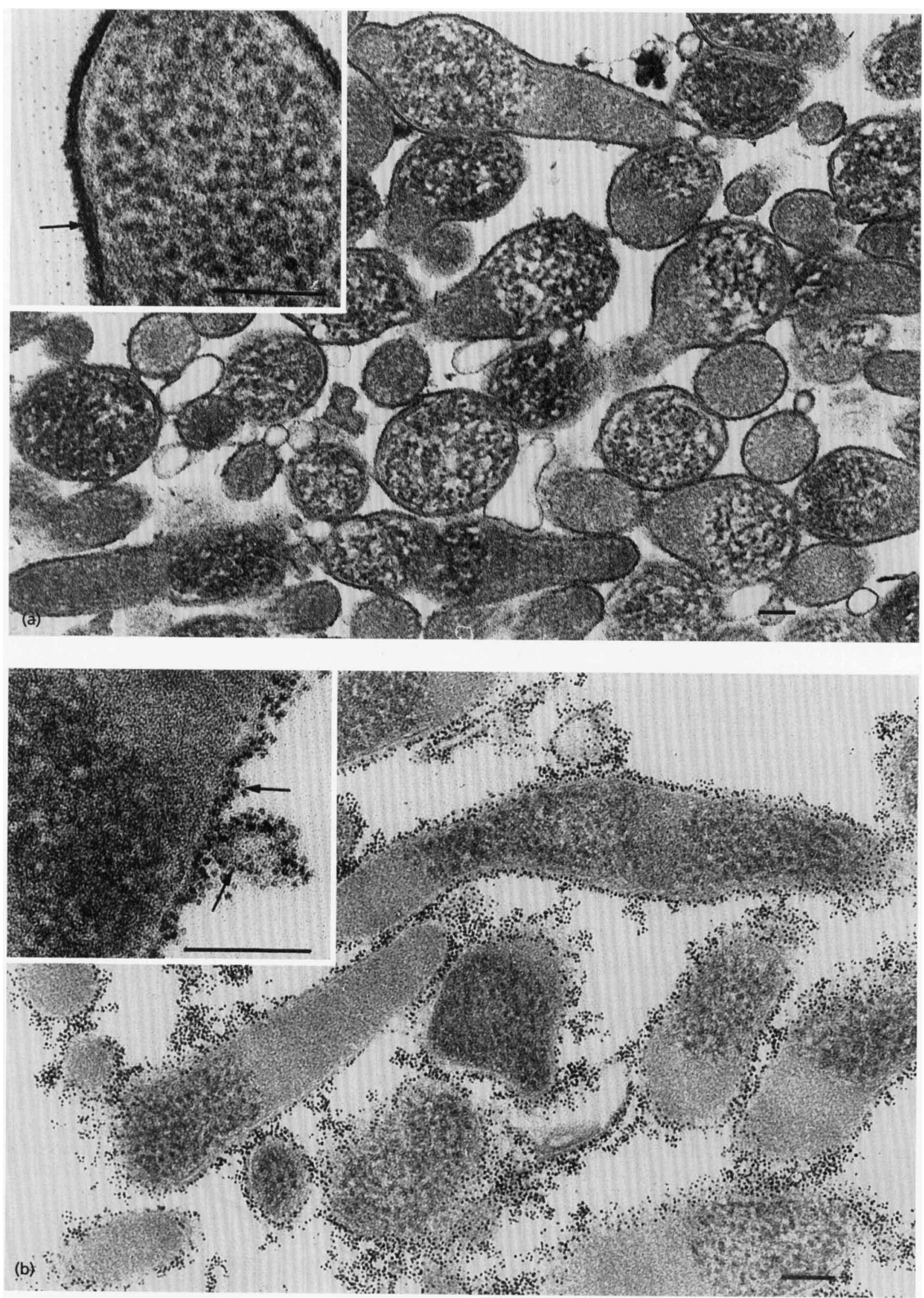

Fig. 1. Ultrastructural analysis of $M$. penetrans cells. Capsular material on the surface of $M$. penetrans cells (strain GTU-546A1) revealed using RR staining (a) or cationized ferritin labelling (b). Arrows indicate the capsule. Bars, $150 \mathrm{~nm}$. 

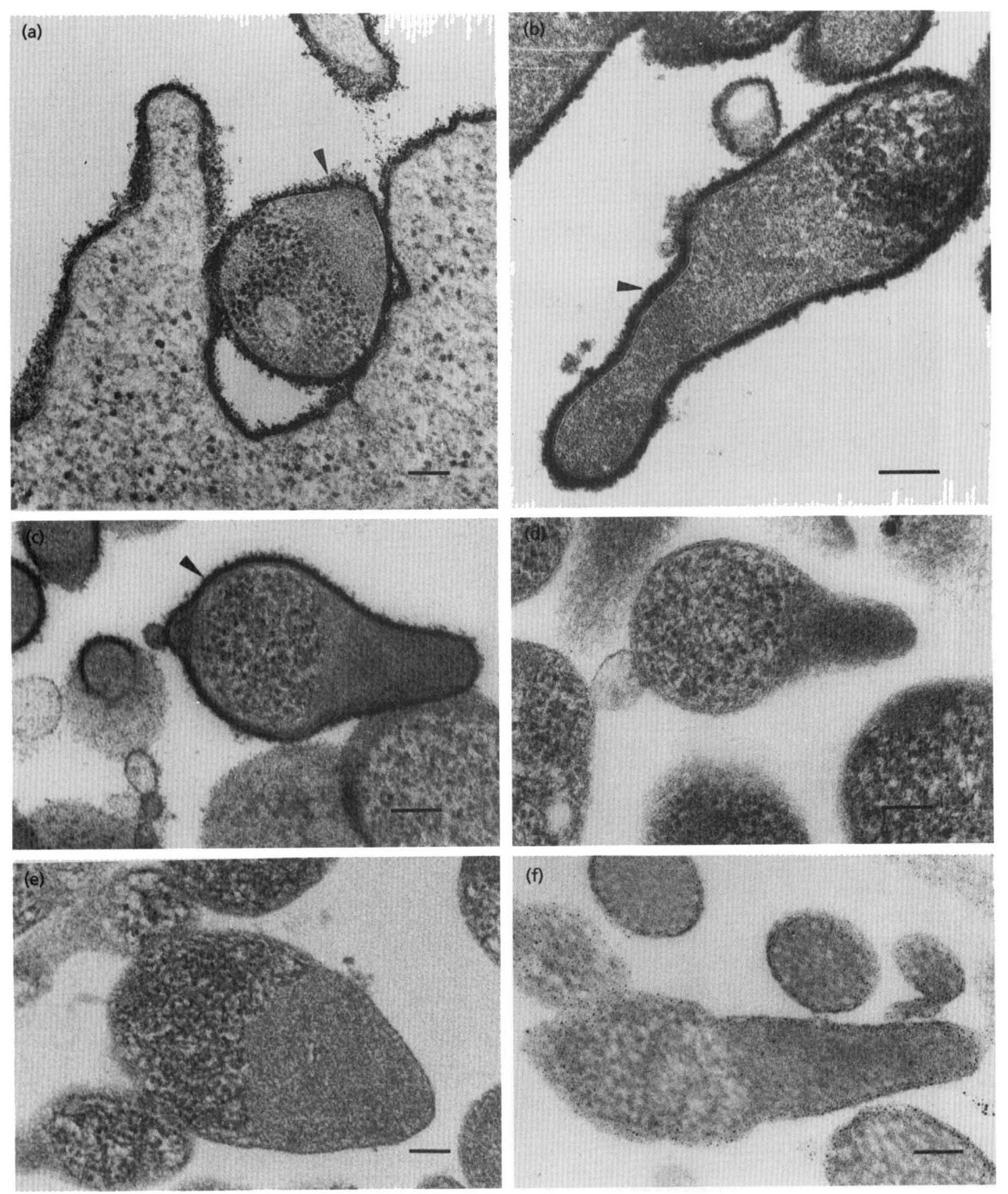

Fig. 2. $M$. penetrans capsule thickness in the presence of eukaryotic cells, in different strains and effect of proteinase $K$ or neuraminidase treatment. (a-e) Samples stained with RR. (a) M. penetrans (type strain) co-cultivated with human PBMC. (b) $M$. penetrans strain HF-2 cultivated in SP-4 medium. (c-e) The $M$. penetrans strain GTU-54-6A1 capsule could not be stained with RR after proteinase $K(d)$ or neuraminidase (e) treatment of the cells, whereas it remained attached to the cells when the mycoplasmas were incubated under the same conditions but without the enzyme (c). ( $f$ ) The $M$. penetrans (type strain) capsule could also be stained with the PATAg reagent. Arrowheads indicate the capsule. Bars, $100 \mathrm{~nm}$.

In contrast to the protease treatment, neuraminidase treatment of the cells did not affect the HMM (Fig. 3, lane 4). EDTA had the same effect on HMM as proteinase $\mathrm{K}$ treatment (Fig. 3, lane 6). Finally, HMM was not detected in the aqueous phase after hot phenol/water extraction, unlike classical lipoglycans 


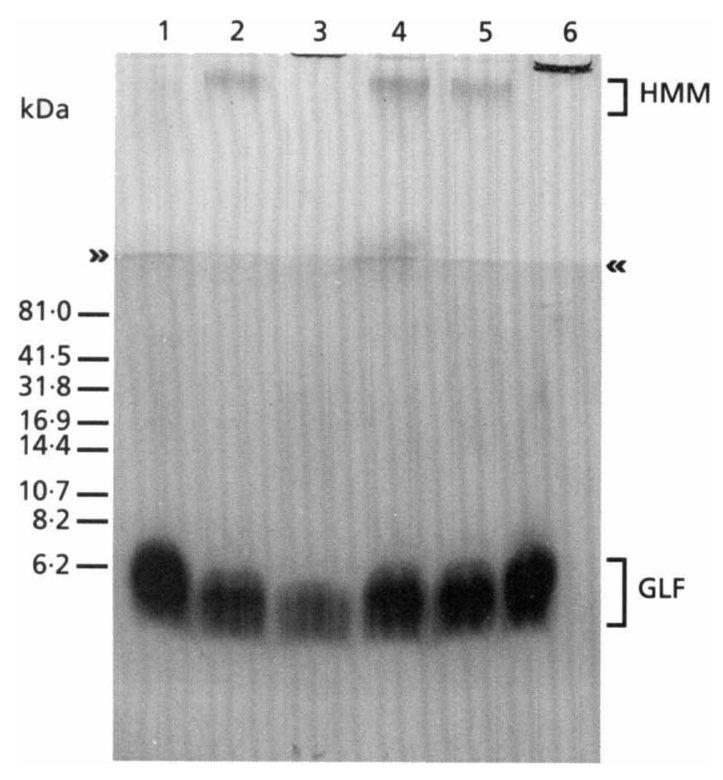

Fig. 3. Identification of HMM from $M$. penetrans cells. SDSPAGE was performed using Tricine buffer and the glycoconjugates were detected by staining with PAS. $M$. penetrans cells were solubilized in the SDS-PAGE sample cocktail and loaded after heating for $5 \mathrm{~min}$ at $95^{\circ} \mathrm{C}$ (lane 1). This heating treatment was omitted for the other samples but the mycoplasma cells were subjected to various treatments prior to solubilization in the SDS-PAGE sample cocktail and loading on the gel: incubation for $30 \mathrm{~min}$ at $37^{\circ} \mathrm{C}$ without added enzyme (lane 2) or with added proteinase K (lane 3) or neuramidase (lane 4), incubation for $20 \mathrm{~min}$ at room temperature without (lane 5) or with (lane 6) $2 \mathrm{mM}$ EDTA. The position of molecular mass markers is indicated on the left of the figure and the interface between the stacking and resolving gels is indicated by the double arrowheads. The HMM and GLF are indicated with brackets.

(Smith, 1992), and was not stained by Coomassie blue or radiolabelled after culture of the mycoplasmas in [1${ }^{14} \mathrm{C}$ ]palmitate-containing medium (data not shown). In addition to the HMM, a $1-6 \mathrm{kDa}$ band was consistently detected in all the M. penetrans extracts tested (Fig. 3, all lanes). This glycoconjugated material was further studied (see below).

\section{Identification of a glycolipid fraction from $\boldsymbol{M}$. penetrans}

In preliminary experiments using a standard procedure for lipoglycan purification (Smith, 1985, 1992) no glycoconjugate could be extracted from $M$. penetrans cells with hot phenol after removal of lipids. All the glycosylated material was found in the methanol/ chloroform phase used for removal of lipids (data not shown). Another method combining proteinase $\mathrm{K}$ digestion with dialysis, previously described for $M$. dispar (Almeida \& Rosenbusch, 1991), was tested (see Methods). The preparation obtained following this protocol was analysed by SDS-PAGE and a $1-6 \mathrm{kDa}$ band was detected after PAS staining (Fig. 4). In this preparation, there was also a minor band $(11-12 \mathrm{kDa})$ (Fig. 4a, lane 5) which was not found in most of the

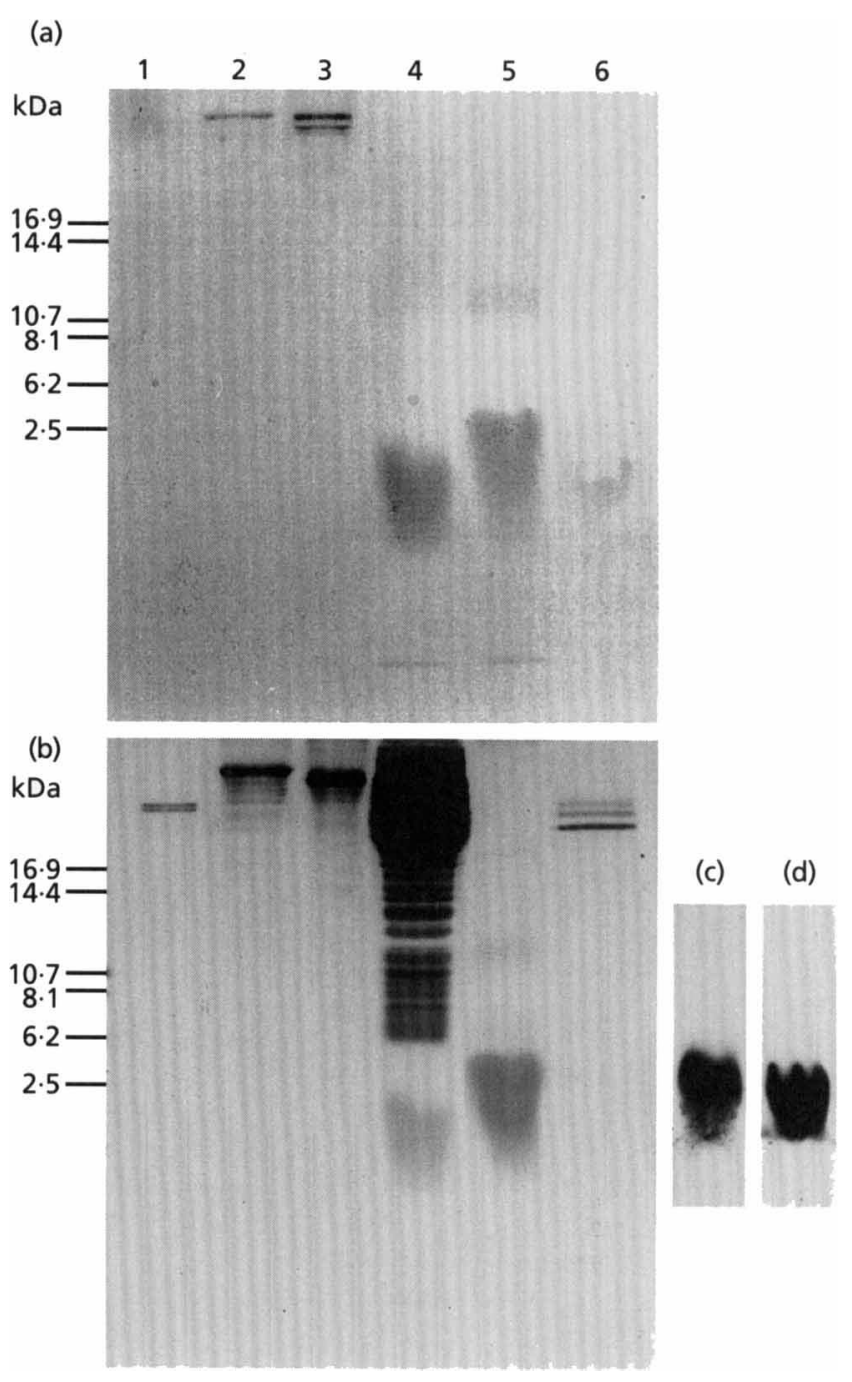

Fig. 4. Electrophoretic analysis of a $M$. penetrans glycolipid fraction. SDS-PAGE was performed on a $17 \%$ polyacrylamide gel. Glycoconjugates were stained with PAS (a) and proteins were subsequently stained with Coomassie blue (b). In (b), the bands correspond to the combination of both detection methods. The samples loaded were creatinase (lane 1), transferrin as a glycoprotein control (lane 2), SP-4 medium (lane 3), $M$. penetrans whole-cell lysate (lane 4), proteinase-Kdigested and dialysed $M$. penetrans whole-cell lysate (lane 5) and the detergent phase of the Triton X-114 extract of $M$. penetrans cells (lane 6). Incorporation of palmitic acid and phosphate in GLF was revealed after cultivation of mycoplasmas with $\left[{ }^{14} \mathrm{C}\right]$ palmitic acid (c) or $\left[{ }^{32} \mathrm{P}^{3} \mathrm{H}_{3} \mathrm{PO}_{4}\right.$ (d). In (c) and (d), proteinase-K-digested and dialysed $M$. penetrans whole-cell lysates were separated and radioactivity was detected by autoradiography.

preparations of $M$. penetrans cells. The $1-6 \mathrm{kDa}$ band was also detected in the $M$. penetrans whole-cell lysates (Fig. 4a, lane 4) but not in the culture medium (Fig. 4a, lane 3). The $1-6 \mathrm{kDa}$ band and the $11-12 \mathrm{kDa}$ band were not stained with Coomassie blue, suggesting that they did not contain protein (Fig. 4 b, lanes 4 and 5).

To detect covalently linked lipids and phosphate groups in the PAS-stained materials, mycoplasmas were cul- 
tivated in the presence of $\left[1-{ }^{14} \mathrm{C}\right]$ palmitic acid or $\left[{ }^{32} \mathrm{P}\right]$ pyrophosphate and the proteinase-K-treated cell lysate was analysed by SDS-PAGE. The $1-6 \mathrm{kDa}$ material incorporated both palmitate and phosphate (Fig. $4 \mathrm{c}, \mathrm{d})$.

M. penetrans cells labelled with $\left[1-{ }^{14} \mathrm{C}\right]$ palmitic acid were extracted with Triton X-114 and cell components phase-partitioned. The detergent phase contained the $1-6 \mathrm{kDa}$ material as assessed by PAS staining (Fig. 4a, lane 6). Quantitative analysis of the radioactivity associated with the $1-6 \mathrm{kDa}$ GLF revealed that $95 \%$ of this material partitioned in the detergent phase (data not shown).

\section{Analysis of the sugar composition of $\boldsymbol{M}$. penetrans GLF by GLC}

The sugar composition of GLF was determined by GLC and was found to be Man:Glc:GlcNAc:GalNAc in a ratio of $1: 6: 1: 2$. This analysis was performed on two independent preparations of GLF and the results obtained were almost identical. No galactose residues were detected. No attempt was made to detect sulfated, phosphorylated or other modified sugars. The sugar composition of a second $M$. penetrans strain (HF-2) was the same.

\section{DISCUSSION}

Electron microscopy using RR staining and cationized ferritin labelling revealed a polyanionic material covering $M$. penetrans cells, including the tip structure believed to mediate cytadherence (Fig. 1). This 11-13 nm capsule was thinner than similar cell surface structures from other mycoplasma species: $20 \mathrm{~nm}$ for $M$. gallisepticum (Tajima et al., 1982), $40 \mathrm{~nm}$ for $M$. byopneumoniae (Tajima \& Yagihashi, 1982), $30 \mathrm{~nm}$ for $M$. mycoides subsp. mycoides (Jones et al., 1965) and $24 \mathrm{~nm}$ for $M$. dispar (Howard \& Gourlay, 1974). The $M$. penetrans capsule was not lost during centrifugation or washing and was therefore not considered a slime (Whitfield, 1988). The capsule was thicker on strain HF2 than on the type strain of M. penetrans (Fig. 2) indicating that capsule thickness varied among different strains. Capsule synthesis may be regulated, as was reported for other mycoplasma species, including $M$. dispar (Almeida \& Rosenbusch, 1991) for which inducible capsule synthesis was demonstrated in vitro in the presence of a soluble factor secreted by bovine lung fibroblasts. Capsule thickness has been associated with virulence in M. byopneumoniae (Tajima \& Yagihashi, 1982) and M. gallisepticum (Tajima et al., 1982). In addition, it has been suggested that capsules of $M$. meleagridis (Green \& Hanson, 1973), M. dispar (Howard \& Gourlay, 1974) and M. pneumoniae (Wilson $\&$ Collier, 1976) play a role in the attachment of bacteria to host cells. Ultrastructural examination indicated an intimate interaction between the capsule of $M$. penetrans and the surface glycoconjugates of the infected eukaryotic cell (Fig. 2a). This interaction suggests a role for the $M$. penetrans capsule in attachment and this possibility is supported by the demonstration that neuraminidase or sodium periodate treatment of the $M$. penetrans cells reduced attachment (Giron et al., 1996). Since the $M$. penetrans capsule was stained with the PATAg reagent and could not be RR-stained after neuraminidase treatment, we concluded that the capsule was composed, at least partially, of polysaccharides. Furthermore, as the $V$. cholerae neuraminidase is known to hydrolyse terminal neuraminic acids from polysaccharides (with a specificity for the bonds $2,3-\alpha->2,6-\alpha->2,8-\alpha-)$, the RR staining and cationized ferritin labelling of the $M$. penetrans capsule are probably due to the presence of acidic (anionic) groups at the extremity of the capsular polysaccharide molecules. This result is still consistent with the inability of neuramidase treatment to remove the HMM seen on SDS-PAGE gels (Fig. 3), as this neuraminidase treament only hydrolyses terminal neuraminic acids without necessarily affecting polysaccharide chain integrity. Furthermore, the fact that proteinase $\mathrm{K}$ treatment of the cells also removed the capsule, without otherwise altering cell morphology, suggested that polypeptides might be involved in the anchoring or stabilization of this material.

To identify the polysaccharide components of the capsule, we looked for glycosylated components by SDS-PAGE and PAS staining. Two types of glycosylated materials of different size were identified (Figs 3, 4). The $M$. penetrans GLF is probably inserted into the plasma membrane as it was shown to possess a lipid moiety. This component is too small to account for the thickness of the capsule, which is more likely to be composed of larger glycoconjugates such as the HMM. Since the capsule was also removed from the cells following similar treatments to those which disrupted the HMM (Fig. 2), the HMM is most likely to be the polysaccharide from this capsule. In addition, the HMM was sensitive to EDTA, which suggests that divalent cations are involved in the maintenance of its structure. Furthermore, since the $M$. penetrans capsule is not a slime, the HMM is probably anchored to the plasma membrane by interactions with components (lipid moieties including glycolipids and polypeptides) which remain to be identified.

The GLF components detected by SDS-PAGE were resistant to proteinase $\mathrm{K}$, partitioned in methanol and in the Triton X-114 detergent phase and contained palmitic acid and phosphate (Fig. 4). This GLF was totally recovered using a proteinase $\mathrm{K}$-dialysis method. When analysed by gas liquid chromatography, it was found to contain Man:Glc:GlcNAc:GalNAc in a ratio of $1: 6: 1: 2$ for both strain GTU-54-6A1 and HF-2. The polymeric nature of sugar residues in GLF was supported by the fact that this material was detected by the method of Kirkeby et al. (1992), which does not detect mono- or disaccharides. The glucose residues may enable the purification of $M$. penetrans GLF by concanavalin A affinity chromatography. Preliminary mass spectrometry data indicated that the GLF contained components ranging from 700 to $1700 \mathrm{Da}$. A major peak for a $1430 \mathrm{Da}$ component was found, which is consistent 
with a diglyceride linked to five or six hexose residues. Further investigations will be necessary to determine the chemical structure of GLF. In M. dispar (Almeida \& Rosenbusch, 1991), a glycosylated component similar to $M$. penetrans GLF was also detected by SDS-PAGE and PAS staining in proteinase-K-digested and dialysed cells. This $M$. dispar material appeared as a single $4 \mathrm{kDa}$ band in $12 \%$ polyacrylamide gels. Using electrophoretic conditions with higher resolution for low-molecularmass glycoconjugates (Lesse et al., 1990), the $M$. penetrans GLF was resolved into two or three bands, which suggested that it contained distinct glycolipids. The GLF was also found to be labelled with radioactive phosphate (Fig. 4d). Within the Mollicutes, the presence of covalently linked phosphate residues in glycolipids has only been reported in some Acholeplasma species (Smith, 1992) and in M. fermentans for the phosphocholine-containing glyco-glycerophospholipids (Matsuda et al., 1995, 1997; Zähringer et al., 1997; BenMenachem et al., 1997). Our results showing the presence of phosphate groups in the GLF suggest that this component could consist of such phosphoglycolipids. However, we cannot exclude the possibility that the GLF is heterogeneous and could correspond to a mixture of different moieties including non-phosphorylated glycolipids, i.e. glycosylacylglycerols, polyterpenol glycosides and/or acylated sugars, co-migrating with phosphorylated polar lipids. In addition, the GLF partitioned with lipoproteins in the detergent phase of the Triton X-114 extract (this study; Ferris et al., 1995). Therefore, it remains to be determined whether the GLF contributed to the reported immuno-stimulant activities of this extract (Feng \& Lo, 1994; Rawadi \& RomanRoman, 1996). Determination of the specific role of the $M$. penetrans capsule in virulence and cytadherence will require the development of capsule-defective mutants.

In this study, we reported for the first time that the $M$. penetrans membrane is surrounded by a capsule composed, at least in part, of polysaccharides. We also identified another glycoconjugate fraction from this mycoplasma. The identification of such cell surface components is of particular interest for $M$. penetrans, which has been shown to adhere to various host cells and to penetrate into their cytoplasmic compartments. Our findings have potential implications for explaining the chronicity of $M$. penetrans infections because the capsule might contribute to evasion of the host immune response and phagocytosis.

\section{ACKNOWLEDGEMENTS}

We thank J. Lemoine for mass spectroscopy analysis, E. Perret and $\mathrm{C}$. Schmitt for technical assistance with electron microscopy and $\mathrm{H}$. Wróblewski for stimulating discussions and reviewing the manuscript. C.B. and O.N. were recipients of fellowships from the Association Claude Bernard and Institut Pasteur, respectively.

\section{REFERENCES}

Almeida, R. \& Rosenbusch, R. (1991). Capsulelike surface material of Mycoplasma dispar induced by in vitro growth in culture with bovine cells is antigenically related to similar structures expressed in vivo. Infect Immun 59, 3119-3125.

Almeida, R., Wannemuehler, M. \& Rosenbusch, R. (1992). Interaction of Mycoplasma dispar with bovine alveolar macrophages. Infect Immun 60, 2914-2919.

Andreev, J., Borovsky, Z., Rosenshine, I. \& Rottem, S. (1995). Invasion of HeLa cells by Mycoplasma penetrans and the induction of tyrosine phosphorylation of a $145-\mathrm{kDa}$ host cell protein. FEMS Microbiol Lett 132, 189-194.

Ben-Menachem, G., Wagner, F., Zähringer, U., Rietschel, E. T. \& Rottem, S. (1997). Antibody response to MfGL-II, a phosphocholine-containing major lipid of Mycoplasma fermentans membranes. FEMS Microbiol Lett 154, 363-369.

Blanchard, A. \& Montagnier, L. (1994). AIDS-associated mycoplasmas. Annu Rev Microbiol 48, 687-712.

Blanchard, A., Gougeon, M.-L. \& Montagnier, L. (1997). Influence of microbial infection on the progression of HIV disease. Trends Microbiol 5, 326-331.

Brenner, C., Neyrolles, O. \& Blanchard, A. (1996). Mycoplasmas and HIV infection: from epidemiology to their interaction with immune cells. Front Biosci 1, 42-54.

Buttery, S. H. (1970). Hapten inhibition of the reaction between Mycoplasma mycoides polysaccharide and bovine antisera. Immunochemistry 7, 305-310.

Buttery, S. H. \& Plackett, P. (1960). A specific polysaccharide from Mycoplasma mycoides. J Gen Microbiol 23, 357-368.

Cross, A. (1990). The biological significance of bacterial encapsulation. Curr Top Microbiol Immunol 150, 87-95.

Feng, S. H. \& Lo, S.-C. (1994). Induced mouse spleen B-cell proliferation and secretion of immunoglobulin by lipid-associated membrane proteins of $M$. fermentans incognitus and $M$. penetrans. Infect Immun 62, 3916-3921.

Ferris, S., Watson, H. L., Neyrolles, O., Montagnier, L. \& Blanchard, A. (1995). Characterization of a major Mycoplasma penetrans lipoprotein and of its gene. FEMS Microbiol Lett 130, 313-320.

Furness, G., Whitescarver, J., Trocola, M. \& DeMaggio, M. (1976). Morphology, ultrastructure, and mode of division of Mycoplasma fermentans, Mycoplasma hominis, Mycoplasma orale, and Mycoplasma salivarium. J Infect Dis 134, 224-229.

Gerard, C. (1990). Purification of glycoproteins. Methods Enzymol 182, 529-539.

Giron, J., Lange, M. \& Baseman, J. (1996). Adherence, fibronectin binding, and induction of cytoskeleton reorganization in cultured human cells by Mycoplasma penetrans. Infect Immun 64, 197-208.

Grau, O., Slizewicz, B., Tuppin, P. \& 10 other authors (1995). Association of Mycoplasma penetrans with human immunodeficiency virus infection. J Infect Dis 172, 672-681.

Green, F. \& Hanson, R. (1973). Ultrastructure and capsule of Mycoplasma meleagridis. J Bacteriol 116, 1011-1018.

Howard, C. J. \& Gourlay, R. N. (1974). An electron-microscopic examination of certain bovine mycoplasmas stained with ruthenium red and the demonstration of a capsule on Mycoplasma dispar. J Gen Microbiol 83, 393-398.

Jones, A. S., Tittensor, J. R. \& Walker, R. T. (1965). The chemical composition of the nucleic acids and other macromolecular constituents of Mycoplasma mycoides var. capri.J Gen Microbiol 40, 405-411.

Kamerling, J. P., Gerwig, G. J., Vliegenthart, J. F. \& Clamp, J. R. (1975). Characterization by gas-liquid chromatography-mass 
spectrometry and proton-magnetic-resonance spectroscopy of pertrimethylsilyl methyl glycosides obtained in the methanolysis of glycoproteins and glycopeptides. Biochem J 151, 491-495.

Kasper, D. L. (1986). Bacterial capsules - old dogmas and new tricks. J Infect Dis 153, 407-415.

Kirkeby, S., Moe, D., Bog-Hansen, T., Garbarsch, C. \& Matthiessen, M.E. (1992). Quantitative PAS assay of some carbohydrate compounds and detergents. $J$ Biochem Biophys Methods 24, 225-238.

Laemmli, U. K. (1970). Cleavage of structural proteins during the assembly of the head of bacteriophage T4. Nature 227, 680-685.

Lesse, A., Campagnari, A., Bittner, W. \& Apicella, M. (1990). Increased resolution of lipopolysaccharides and lipooligosaccharides utilizing tricine-sodium dodecyl sulfate-polyacrylamide gel electrophoresis. J Immunol Methods 126, 109-117.

Lo, S.-C., Hayes, M. M., Wang, R. Y., Pierce, P., Kotani, H. \& Shih, J. W.-K. (1991). Newly discovered mycoplasma isolated from patients infected with HIV. Lancet 338, 1415-1416.

Lo, S.-C., Hayes, M. M., Kotani, H., Pierce, P., Wear, D., Newton, P., Tully, J. \& Shih, J. W.-K. (1993). Adhesion onto and invasion into mammalian cells by Mycoplasma penetrans: a newly isolated mycoplasma from patients with AIDS. Mod Patbol 6, 276-280.

Marshall, A., Miles, R. \& Richards, L. (1995). The phagocytosis of mycoplasmas. J Med Microbiol 43, 239-250.

Matsuda, K., Harasawa, R., Li, J. L., Kasama, T., Taki, T., Handa, S. \& Yamamoto, N. (1995). Identification of phosphocholine-containing glycoglycerolipids purified from Mycoplasma fermentansinfected human helper T-cell culture as components of $M$. fermentans. Microbiol Immunol 39, 307-313.

Matsuda, K., Harasawa, R. \& Yamamoto, N. (1997). Phosphocholine-containing glycoglycerolipids (GGPL-I and GGPL-III) are species-specific major immunodeterminants of Mycoplasma fermentans. Biochem Biophys Res Commun 233, 644-649.

Moxon, E. \& Kroll, J. (1990). The role of bacterial polysaccharide capsules as virulence factors. Curr Top Microbiol Immunol 150, $65-85$.

Rawadi, G. \& Roman-Roman, S. (1996). Mycoplasma membrane lipoproteins induce proinflammatory cytokines by a mechanism distinct from that of lipopolysaccharide. Infect Immun 64, $637-643$.

Robertson, J. \& Smook, E. (1976). Cytochemical evidence of extramembraneous carbohydrates on Ureaplasma urealyticum (T-strain mycoplasma). J Bacteriol 128, 658-660.

Rosenbusch, R. \& Minion, F. (1992). Cell envelope: morphology and biochemistry. In Mycoplasmas. Molecular Biology and Pathogenesis, pp. 73-77. Edited by J. Maniloff. Washington, DC: American Society for Microbiology.
Sadawardeker, J., Sloneker, J. \& Jeanes, A. (1965). Quantitative determination of monosaccharides as their alditol acetates by gas liquid chromatography. Anal Biochem 37, 1602-1604.

Sasaki, Y., Blanchard, A., Watson, H. L., Garcia, S., Dulioust, A., Montagnier, L. \& Gougeon, M.-L. (1995). In vitro influence of Mycoplasma penetrans on activation of peripheral T-lymphocytes from healthy donors or HIV-infected individuals. Infect Immun 63, 3916-3921.

Smith, P. F. (1985). Detection of lipoglycans in ureaplasmas. $J$ Bacteriol 162, 611-614.

Smith, P. F. (1992). Membrane lipids and lipopolysaccharide structures. In Mycoplasmas. Molecular Biology and Pathogenesis, pp. 79-91. Edited by J. Maniloff. Washington, DC: American Society for Microbiology.

Tajima, M. \& Yagihashi, T. (1982). Interaction of Mycoplasma byopneumoniae with the porcine respiratory epithelium as observed by electron microscopy. Infect Immun 37, 1162-1169.

Tajima, M., Yagihashi, T. \& Miki, Y. (1982). Capsular material of Mycoplasma gallisepticum and its possible relevance to the pathogenic process. Infect Immun 36, 830-833.

Taylor-Robinson, D., Furr, M., Davies, H., Manchee, R. \& Bové, J. (1981). Mycoplasmal adherence with particular reference to the pathogenicity of Mycoplasma pulmonis. Isr J Med Sci 17, 599-603.

Thiery, J. P. (1967). Mise en évidence des polysaccharides sur coupes fines en microscopie électronique. J Microsc 6, 987-1018.

Tully, J., Whitcomb, R., Clarck, H. \& Williamson, D. (1977). Pathogenic mycoplasmas: cultivation and vertebrate pathogenicity of a new spiroplasma. Science 195, 892-894.

Wang, R., Shih, J., Weiss, S., Grandinetti, T., Pierce, P., Lange, M., Alter, H., Wear, D., Davies, C., Mayur, R. \& Lo, S.-C. (1993). Mycoplasma penetrans infection in male homosexuals with AIDS: high seroprevalence and association with Kaposi's sarcoma. Clin Infect Dis 17, 724-729.

Whitfield, C. (1988). Bacterial extracellular polysaccharides. Can $J$ Microbiol 34, 415-420.

Wilson, M. \& Collier, A. (1976). Ultrastructural study of Mycoplasma pneumoniae in organ culture. J Bacteriol 125, 332-339.

Zahringer, U., Wagner, F., Rietschel, E. T., Ben-Menachem, G., Deutsch, J. \& Rottem, S. (1997). Primary structure of a new phosphocholine-containing glycoglycerolipid of Mycoplasma fermentans. J Biol Chem 17, 26262-26270.

Received 24 September 1997; revised 15 January 1998; accepted 26 January 1998. 